Research Article

\title{
Mechanical Properties and Thermal Conductivity of Aerogel-Incorporated Alkali-Activated Slag Mortars
}

\author{
Levent Bostanci ${ }^{1}$ and Ozlem Celik Sola $\mathbb{D D}^{2}$ \\ ${ }^{1}$ School of Advanced Vocational Studies, Beykent University, Istanbul, Turkey \\ ${ }^{2}$ Department of Civil Engineering, Faculty of Engineering, Istanbul University, Istanbul, Turkey
}

Correspondence should be addressed to Ozlem Celik Sola; celik@istanbul.edu.tr

Received 24 March 2018; Revised 8 June 2018; Accepted 25 June 2018; Published 5 August 2018

Academic Editor: Li Li

Copyright (c) 2018 Levent Bostanci and Ozlem Celik Sola. This is an open access article distributed under the Creative Commons Attribution License, which permits unrestricted use, distribution, and reproduction in any medium, provided the original work is properly cited.

\begin{abstract}
Compressive strength, thermal conductivity coefficient, and porosimetric properties of alkali-activated slag (AAS) mortars containing silica aerogel were investigated experimentally in this study. For this purpose, slag mortar mixtures at $0.75 \%$ and $1.0 \%$ aerogel content ratios were prepared, and these mortar mixtures were activated with lithium carbonate $\left(\mathrm{Li}_{2} \mathrm{CO}_{3}\right)$ at $0.03 \%$ and $1.50 \%$ dosage rates. Mortar samples were exposed to curing process in water for 2, 7, and 28 days, and the samples, which completed the curing stage, were subjected to the compressive strength test. The porosimetry test and the thermal conductivity coefficient measurement were carried out following the compressive strength test on 28-day samples. The varying aerogel content rate in the mixtures and the effects of the dosage of $\mathrm{Li}_{2} \mathrm{CO}_{3}$ on the gel, capillary, and macropore distributions, and the effect of changing porosimetric properties on compressive strength and thermal conductivity coefficient were analyzed in detail. Experimental studies have shown that AAS mortars including an optimum $0.75 \%$ aerogel content rate and $0.03 \% \mathrm{Li}_{2} \mathrm{CO}_{3}$ activation provided a compressive strength of $34.1 \mathrm{MPa}$ and a thermal conductivity coefficient of $1.32 \mathrm{~W} / \mathrm{mK}$. Aerogel addition provides a partial compressive strength increase at 7- and 28day samples while it also causes maximum strength loss of $5.0 \%$ at 2 -day samples.
\end{abstract}

\section{Introduction}

Despite its many useful functional and economical features such as low energy and cost requirements during its production and ensuring an easy production of the structural element in building construction, cement makes a negative contribution to global warming by creating $5-8 \%$ of $\mathrm{CO}_{2}$ emissions [1]. Therefore, it is required to use the environment-friendly, easy to recycle materials with low $\mathrm{CO}_{2}$ emissions in material technology and to improve the environment-friendly properties of existing materials, as such in all sectors [2]. For this purpose, blast furnace slag which can be characterized as a waste-type binder can be replaced by the clinker in the binder matrix by means of its features including high sulfate resistance, high ultimate strengths, and low $\mathrm{CO}_{2}$ release in particular [3].

In cement technology, composite binders with reduced clinker ratio have been designed by partial replacement of clinker through supplementary materials such as pozzolan, granulated blast furnace slag, and limestone for many years. In general, significant losses are observed especially at longterm mechanical strengths at replacement of $50 \%$ or more. Thus, alkali-activated alternative binder materials of which mechanical strengths are improved by means of alkali activators are needed [4].

Alkali-activated slag is a kind of binder which is formed with the chemical reaction of an activator and a slag precursor, especially in countries where slag production is prevalent [5]. Although it has found wide use in recent years, it has not entered the regulations of most countries as a different design material from cement yet [6].

The main hydration products in alkali-activated slag mortars consist of calcium aluminosilicate hydrate gels at low $\mathrm{Ca} / \mathrm{Si}$ rates, hydrocalcite, and other mineral phases [7]. The anion type of the selected alkali activator is vital in the development of mechanical strengths and the setting time, especially when the $\mathrm{pH}$ value exceeds 12 [8]. Both initial and 
final setting times are shortened with the increase in activator dosage [9].

In alkali-activated slag mortars, with increasing activator dosages, higher compressive strengths are observed in addition to shortening setting times. The amount of replacement by weight within the binder material is also vital on the compressive strengths of the waste-activated mortars. Najimi et al. activated the $30 \%, 50 \%$, and $70 \%$ slagincorporated binder using sodium hydroxide $(\mathrm{NaOH})$ and sodium silicate solutions in their experimental study. In 28day compressive strength tests, the strength was found to be varying from 20.9 to $43.2 \mathrm{MPa}$ [10].

Aiming to obtain cement-like strengths in slag mortars, different porosimetric parameters are determined compared to cement mortars. Alkali-activated slag mortars have a different pore structure than conventional cement mortars. The total porosity value of the $\mathrm{Na}_{2} \mathrm{SiO}_{3}$-activated slag mortar at the third day might be lower than the total porosity value of the conventional cement mortar at the ninetieth day [11]. Pore volume of micropores increases and capillary pores decreases with the increment of slag content in alkaliactivated slag mortars compared to conventional cement mortars [12]. In experimental studies of Shi et al., the pore diameters above $100 \mathrm{~nm}$ represent $11.45 \%$ of total pore volume in cement mortars, while the proportion is only $3.92 \%$ of total pore volume in alkali-activated slag mortars [13].

Experimental studies with ecological purposes for reducing the requirement for conventional cement are not conducted only due to the high $\mathrm{CO}_{2}$ release of the cement but also for the conservation of energy by lowering the high thermal conductivity coefficient detected in the cement mortars. In order to carry out this task, the coefficient of thermal conductivity can be reduced in mortars by means of forming a suitable pore structure in cement matrix with additive materials having the low thermal conductivity coefficients. Pore structure designs could be made up to the level of "foam concrete" depending on thermal conductivitycompressive strength optimization [14].

Polyurethane foam, phenolic foam, mineral wool, polystyrene, fiberglass, rock wool polystyrene, cork, and so on are used as heat insulation materials in current material technology. In addition to these materials, silica aerogels firstly synthesized by Kistler in 1931 have been used as additive materials in experimental studies for insulation purposes in concrete technology in recent years. Considering the thermal conductivity coefficients of other insulation materials are in the range of $0.018-0.048 \mathrm{~W} / \mathrm{mK}$, the silica aerogels have extremely superior thermal insulation ability for a solid material with very low thermal conductivity coefficients $(0.0034-0.022 \mathrm{~W} / \mathrm{mK})$ [15-17]. The lightness and low-volume structure of the aerogels make silica aerogels attractive compared to all other fibrous and foam-based insulation materials besides their high durability properties [18].

In previous studies, it was stated that aerogel particles are stable during the hydration of cementitious materials and aerogel particles are not degraded by the process of hydration. However, the mortar compressive strength and
TABle 1: The physical properties of the aerogel used in the experiments.

\begin{tabular}{lc}
\hline Surface area $\left(\mathrm{m}^{2} / \mathrm{gr}\right)$ & $790-840$ \\
Pore diameter $(\mathrm{nm})$ & $8-10$ \\
Porosity $(\%)$ & $>94 \%$ \\
Apparent density $\left(\mathrm{kg} / \mathrm{m}^{3}\right)$ & $90-100$ \\
Surface group & $-\mathrm{OH}$ \\
\hline
\end{tabular}

TABLE 2: Chemical composition of $\mathrm{Li}_{2} \mathrm{CO}_{3}$.

\begin{tabular}{lc}
\hline Component & $(\%)$ \\
$\mathrm{Li}_{2} \mathrm{CO}_{3}$ & Minimum 99 \\
$\mathrm{Cl}$ & Maximum 0.02 \\
$\mathrm{Na}_{2} \mathrm{O}$ & Maximum 0.20 \\
$\mathrm{CaO}$ & Maximum 0.05 \\
$\mathrm{Fe}_{2} \mathrm{O}_{3}$ & Maximum 0.01 \\
$\mathrm{SO}_{4}$ & Maximum 0.20 \\
\hline
\end{tabular}

thermal conductivity coefficient decrease in proportion to the increase of aerogel content [19].

In this study, unlike previous experimental studies, aerogel contribution was made to alkali-activated slag (AAS) mortar instead of conventional cement mortar, and it was added at the rates of $0.75 \%$ and $1.0 \%$. Alkali activation was performed by activation of slag mortar with lithium carbonate $\left(\mathrm{Li}_{2} \mathrm{CO}_{3}\right)$ in order to minimize the probable compressive strength losses that could be caused by the lower activation ability of the slag material representing the half of the composite binder material compared to the clinker.

\section{Materials and Methods}

\subsection{Materials}

2.1.1. Binder. Composite binder material, which consists of CEM I type $42.5 \mathrm{R}$ Portland cement and granulated blast furnace slag with $50 \%$ by weight for each, was preferred in the mortar mixture produced within the scope of experimental studies. Granulated blast furnace slag and Portland cement are supplied by Bolu Cement Co.

2.1.2. Sand. Standard Rilem sand, which is packed and supplied from Bolu Cement Co., was used in mortar mixtures. The density of sand used in the experiments was determined as $1.352 \mathrm{~kg} / \mathrm{dm}^{3}$, and the specific gravity was 2.563 .

2.1.3. Aerogel. Silica-based hydrophilic aerogels are used to increase thermal insulation in mortar mixtures. Silica aerogel was produced by Ensate Yalıtım Mühendislik Proje San. Tic ve Ltd. Şti and supplied from the same company. The physical properties of the hydrophilic aerogel are given in Table 1.

2.1.4. Lithium Carbonate. Lithium carbonate $\left(\mathrm{Li}_{2} \mathrm{CO}_{3}\right)$, which is rarely used in previous experimental studies, was preferred as the alkali activator in mortar mixtures. This activator was obtained from Sorel Sanayi Ürünleri Tic. 
TABle 3: Physical composition of $\mathrm{Li}_{2} \mathrm{CO}_{3}$.

\begin{tabular}{lc}
\hline Appearance & Free-flow powder \\
\hline Humidity $(\%)$ & $0.3-0.9$ \\
Unit weight $\left(\mathrm{kg} / \mathrm{m}^{3}\right)$ & $850-900$ \\
d50 granulometric analysis (micron) & Maximum 6.9 \\
d97 granulometric analysis (micron) & Maximum 20
\end{tabular}

Ltd. Sti. In Tables 2 and 3, the chemical and physical properties of $\mathrm{Li}_{2} \mathrm{CO}_{3}$ are presented.

2.2. Mix Proportions. In the experimental studies, four mixtures of mortars were prepared for the production of alkali-activated slag mortars. Standard Rilem sand and composite binder, which consist of cement and granulated blast furnace slag, were used in all mortar mixtures. The thermal insulation target in the mortar samples was tried to be provided by the silica-based hydrophilic aerogel content at $0.75 \%$ and $1.00 \%$ rates. Slag mortars were activated with $\mathrm{Li}_{2} \mathrm{CO}_{3}$ in order to increase binding activity of the granulated blast furnace slag, which is about $50 \%$ of the binder material. $\mathrm{Li}_{2} \mathrm{CO}_{3}$ was used in mortar mixtures at the rates of $0.03 \%$ and $1.50 \%$ by weight. In mortar mixtures, $50 \%$ of the binder material used in the mortar mixtures is composed of cement while the remaining $50 \%$ of the material is designed as the sum of slag, aerogel, and $\mathrm{Li}_{2} \mathrm{CO}_{3}$. Furthermore, the proportion of water/binder material was adjusted as 0.50 in all mixtures. Mixture ratios of the alkali-activated slag mortars are given in Table 4 .

2.3. Curing Conditions and Testing. In the scope of the experimental studies, three prismatic mortar samples with dimensions of $40 \times 40 \times 160 \mathrm{~mm}$ were produced for each of 4 different mixtures designed at different aerogel content rates and $\mathrm{Li}_{2} \mathrm{CO}_{3}$ dosages, and the samples were subjected to curing process in water during 2,7 , and 28 days. The samples which completed the curing session were subjected to compressive strength test through ToniTechnik brand and ToniNORM/Toni TROL model device. Mercury intrusion porosimetry and thermal conductivity coefficient measurements were carried out on the parts of the 28-day specimens, which were subjected to compressive strength, after the strength test performed in consistent with TS EN 196-1 standards that define cement strength tests.

Mercury intrusion porosimetry experiments were implemented using a Micromeritics device. Porosimetric properties of the mortar samples were determined by means of the device, and the results of strength and thermal conductivity coefficient were examined by porosimetric parameters.

Thermal conductivity coefficient measurements were carried out using a C-Therm/Tci thermal conductivity device. According to the device specifications, the thermal conductivity coefficient measurement can be carried out on specimen parts subjected to compressive strength without special sample preparation for conductivity determination. Thermal conductivity coefficient measurements were repeated five times for each specimen.

\section{Results and Discussion}

3.1. Setting Time Results. The setting time results of the aerogel-incorporated AAS mortars are shown in Table 5. The varying activator dosage and aerogel content are highly effective both in the initial and final setting times.

S2 and S4 specimens have the earliest initial setting times of 75 and 85 minutes and final setting times of 180 and 195 minutes, respectively. Since these samples are the highest $\mathrm{Li}_{2} \mathrm{CO}_{3}$-dosed $(1.50 \%)$ samples in experimental studies, the hydration progresses rapidly due to the effect of high activator dosage. Quite long initial setting times of the samples in $\mathrm{S} 1$ and $\mathrm{S} 3$ are related to the minimum $\mathrm{Li}_{2} \mathrm{CO}_{3}$ dosage $(0.03 \%)$ in the samples.

The minor difference between the initial and final setting times of the S2 and S4 samples which have equal activator dosages occurs as a result of the difference in aerogel content rates. The S4 sample that has $1.0 \%$ aerogel content has slightly later initial and final setting times than the sample S2 with $0.75 \%$ aerogel ratio.

3.2. Compressive Strength Results. In Table 6, the compressive strength test results of aerogel-incorporated AAS mortars on days 2, 7, and 28 were presented. The compressive strengths of 2 days in mortar specimens with different aerogel content ratios and activator dosages are in the range of 12.1-14.5 MPa, while the compressive strengths of 7 and 28 days are varying within the ranges of $19.1-23.8 \mathrm{MPa}$ and 34.1-36.9 MPa, respectively.

The S2 sample (14.5 MPa) with the highest compressive strength among the compressive strength results of the 2-day samples, includes $0.75 \%$ aerogel content and $1.50 \% \mathrm{Li}_{2} \mathrm{CO}_{3}$ activator dosage. The $\mathrm{S} 3$ sample at which the minimum compressive strength $(12.1 \mathrm{MPa})$ is obtained includes $1.0 \%$ aerogel additive and $0.03 \%$ activator dosage. The difference of $19.8 \%$ determined between 2-day compressive strength results on the S2 sample compared to the S3 sample occurs due to the $\mathrm{Li}_{2} \mathrm{CO}_{3}$ effect which is increasing from $0.03 \%$ to $1.50 \%$ in the mortar mixtures. Similarly, compressive strength differences of $14.1 \%$ between S1 and S2 (0.75\%) samples and 15.7\% between S3 and S4 (1.0\%) samples with equal aerogel content is an indicator of the positive effect of increasing $\mathrm{Li}_{2} \mathrm{CO}_{3}$ dosage on the compressive strengths. Evaluating the compressive strength for the equal $\mathrm{Li}_{2} \mathrm{CO}_{3}$ dosages, the determined compressive strength losses of $4.9 \%$ and $3.5 \%$ between the samples $\mathrm{S} 1-\mathrm{S} 3$ and S2-S4, respectively, are related to increasing aerogel content rate in the mortar mixtures.

The S4 sample (23.8 MPa), with the highest compressive strength among the compressive strength test results of the 7-day samples, includes 1.0\% aerogel content and 1.50\% $\mathrm{Li}_{2} \mathrm{CO}_{3}$ activator dosage. The second sample, in which the second highest compressive strength is determined, also contains a $1.50 \% \mathrm{Li}_{2} \mathrm{CO}_{3}$ dosage. $\mathrm{S} 1$ and $\mathrm{S} 3$ samples, in which the lowest compressive strengths are obtained, include $0.03 \% \mathrm{Li}_{2} \mathrm{CO}_{3}$ dosages. For 7 -day compressive strength test results, compressive strength difference between samples which have the maximum and minimum strengths is 
TABLE 4: Mixture ratios of the aerogel-incorporated AAS mortar samples.

\begin{tabular}{|c|c|c|c|c|c|c|c|}
\hline Mix & Aerogel (wt.\%) & $\mathrm{Li}_{2} \mathrm{CO}_{3}$ (wt.\%) & Slag (wt.\%) & Cement (wt.\%) & Water/cement & Water (ml) & Sand $(\mathrm{g})$ \\
\hline S1 & 0.75 & 0.03 & 49.22 & 50 & \multirow{4}{*}{0.50} & \multirow{4}{*}{225} & \multirow{4}{*}{1350} \\
\hline S2 & 0.75 & 1.5 & 47.75 & 50 & & & \\
\hline S3 & 1 & 0.03 & 48.97 & 50 & & & \\
\hline S4 & 1 & 1.5 & 47.5 & 50 & & & \\
\hline
\end{tabular}

TABLE 5: Setting time test results of the aerogel-incorporated AAS mortar samples.

\begin{tabular}{lcc}
\hline Mix number & $\begin{array}{c}\text { Initial setting } \\
\text { time (minimum) }\end{array}$ & $\begin{array}{c}\text { Final setting } \\
\text { time }(\text { minimum })\end{array}$ \\
\hline S1 & 315 & 360 \\
S2 & 75 & 180 \\
S3 & 315 & 360 \\
S4 & 85 & 195 \\
\hline
\end{tabular}

$24.6 \%$. The strength increments of 0.1 and $0.9 \mathrm{MPa}$ were determined between the compressive strength of S1-S3 and S2-S4 samples, which have equal $\mathrm{Li}_{2} \mathrm{CO}_{3}$ dosages, with increasing aerogel contribution.

The compressive strength test results of the 28-day samples are very similar to those of the 7-day samples. S4 and $\mathrm{S} 2$ samples, which have the highest $\mathrm{Li}_{2} \mathrm{CO}_{3}$ dosages, provide maximum strength values among the compressive strength results of the 28 -day samples. A $0.8 \%$ difference between the compressive strength results of these two samples with the highest strength values is observed. This difference obtained in the equivalent activator dosage is important in terms of determining higher strength in the sample including higher aerogel content rate as in the 7-day compressive strength results. The positive effect of the activator dosage on the compressive strength is also evident in the results of the 28-day samples since the sample with the activator dosage of $0.03 \%$ has the lowest value with the value of S1 of 34.1 MPa. The strength increases of 1.4 and $0.3 \mathrm{MPa}$ were determined between the compressive strength of $\mathrm{S} 1-\mathrm{S} 3$ and $\mathrm{S} 2-\mathrm{S} 4$ samples with equal $\mathrm{Li}_{2} \mathrm{CO}_{3}$ dosages, with incremental aerogel contribution.

3.3. MIP Test Results. The MIP test results of aerogelincorporated AAS mortars determined at the end of 28 day curing time are presented in Table 7 . The total porosity values in mortar specimens with different aerogel content ratios and activator dosages are varying in the range of $11.46-15.53 \%$. Considering test results, median pore diameter-area values were found to change from 5.8 to $8.8 \mathrm{~nm}$, and median pore diameter-volume values were observed to vary from 32.7 to $42.3 \mathrm{~nm}$.

The effect of the porosity parameters (median pore diameter-volume, median pore diameter-area, and total porosity) given in Table 7 on pore size distribution of mortar samples is presented in Figure 1. In the S2 sample, in which maximum total porosity of $15.53 \%$ was detected, there are maximum porosities in the diameter ranges of 10,000 100,000 and above $100,000 \mathrm{~nm}$ (5.63\% and $7.07 \%$, resp.) unlike other samples. The total porosity value can reach to
TABLE 6: Compressive strength test results of the aerogel-incorporated AAS mortar samples.

\begin{tabular}{lccc}
\hline \multicolumn{4}{c}{ Compressive strength $(\mathrm{MPa})$} \\
Mix & 2 days & 7 days & 28 days \\
\hline S1 & 12.7 & 19.1 & 34.1 \\
S2 & 14.5 & 22.9 & 36.6 \\
S3 & 12.1 & 19.2 & 35.6 \\
S4 & 14 & 23.8 & 36.9 \\
\hline
\end{tabular}

$15.48 \%$ in the S3 sample by means of the porosity distribution determined in the same diameter ranges $(5.36 \%$ and $4.98 \%$, resp.). The total porosity values of S1 and S4 are lower than those of S2 and S3 since there is no porosity in the diameter ranges of 10,000-100,000 and above 100,000 nm. The total porosity value of the S4 sample (13.60\%) is higher than that of the S1 sample (11.46\%) due to the higher porosity of the sample $S 4$ in the range of $1,000-10,000 \mathrm{~nm}$ compared to that of the sample S1.

Figure 2 shows the relationship between median pore diameter-area and total porosity values in the mortar samples. The total porosity value tends to decrease due to increasing median pore diameter-area in the mortar samples. As a result of the porosimetry analysis, the highest and lowest diameters were determined on the $\mathrm{S} 1$ sample $(8.8 \mathrm{~nm})$ and on the S3 sample $(5.8 \mathrm{~nm})$, respectively. The minimum total porosity value $(11.46 \%)$ was determined by means of the maximum diameter of the S1 sample. In S3, a very high total porosity $(15.48 \%)$ was determined despite the lowest diameter. Samples S1 and S3, where the lowest and highest diameters are determined, are also the lowest $\mathrm{Li}_{2} \mathrm{CO}_{3}$-dosaged samples. In the equal $\mathrm{Li}_{2} \mathrm{CO}_{3}$ dosages, the aerogel content rate varying by $0.25 \%$ is quite effective on median pore diameters.

In Figure 3, the relationship between median pore diameter-area and median pore diameter-volume in mortar samples is shown. In the samples with $0.03 \%$ activator dosage, higher median pore diameter-volume values were obtained compared to the ones with $1.50 \%$ activator dosage despite the varying aerogel content ratio. The highest median pore diameter-volume is observed at S1 which has also the highest median pore diameter-area. Examining the compressive strengths obtained after 28-day curing time, pore diameter forming at maximum level results in obtaining the minimum compressive strengths in the S1 sample, even though the sample provides maximum the median pore diameter-area and the median pore diameter-the volume values compared to the other samples.

Figure 4 shows the relationship between the median pore diameter-volume and 28-day compressive strengths in the mortar samples. Diameter values for aerogel content rates of 
TABLE 7: MIP test results of aerogel-incorporated AAS mortars.

\begin{tabular}{lccc}
\hline Mix number & Median pore diameter-area $(\mathrm{nm})$ & Median pore diameter-volume $(\mathrm{nm})$ & Total porosity $(\%)$ \\
\hline S1 & 8.8 & 42.3 & 11.46 \\
S2 & 6 & 39.4 & 15.53 \\
S3 & 5.8 & 39.5 & 15.48 \\
S4 & 6.6 & 32.7 & 13.60 \\
\hline
\end{tabular}

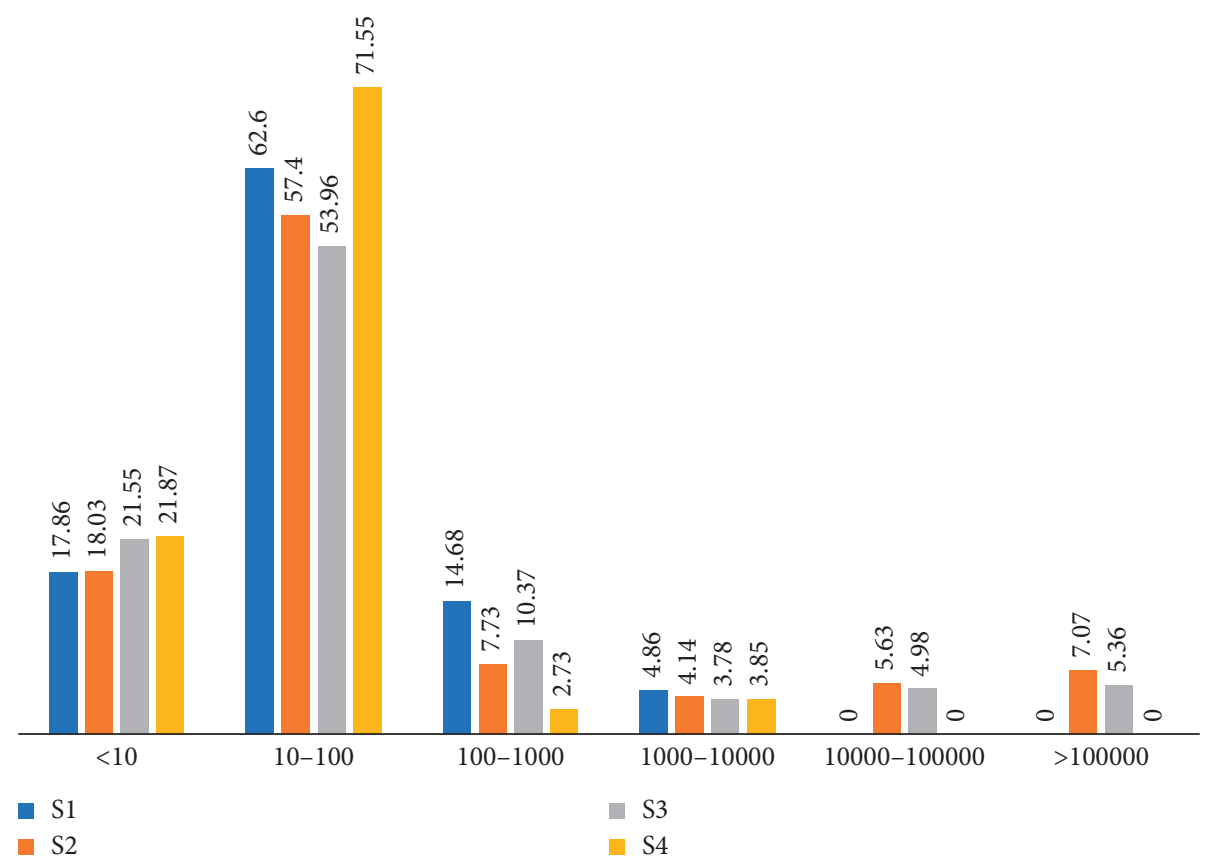

FIgURE 1: Content of pores in mortars.

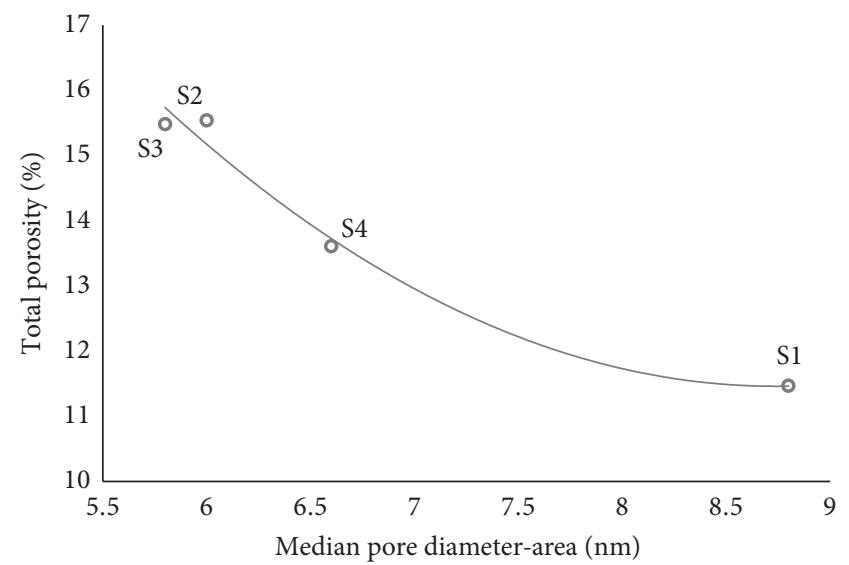

FIgURE 2: Relation between median pore diameter-area and total porosity.

0.75 and $1.0 \%$ are at a minimum of $32 \mathrm{~nm}$. The compressive strengths of the samples decrease without any exception depending on the increasing median pore diameter-volume values. Similar compressive strengths of 35.5-36.6 MPa were found in samples S2 and S3 which have also nearly the same median pore diameter-volume values of $39.4-39.5 \mathrm{~nm}$. For the samples S1 and S4, the diameter difference of $9.6 \mathrm{~nm}$

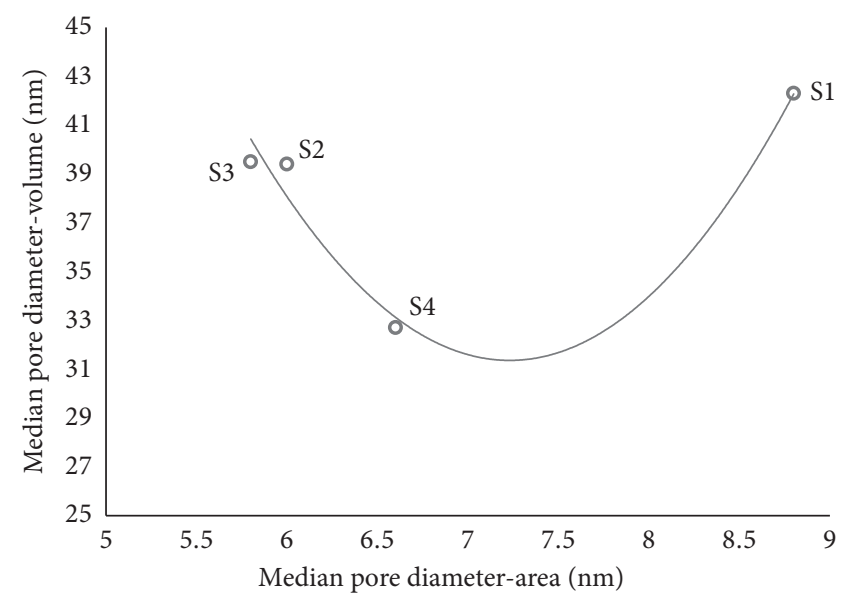

FIgURE 3: Relation between median pore diameter-area and median pore diameter-volume.

determined at the median pore diameter-volume value allow an increase of $8.2 \%$ in compressive strength of the S4 sample.

As a result of the increase in hydration products formed by the activator dosing which increases in equal aerogel content, the median pore diameter-volume is decreasing. The reduction of median pore diameters-volume is caused 


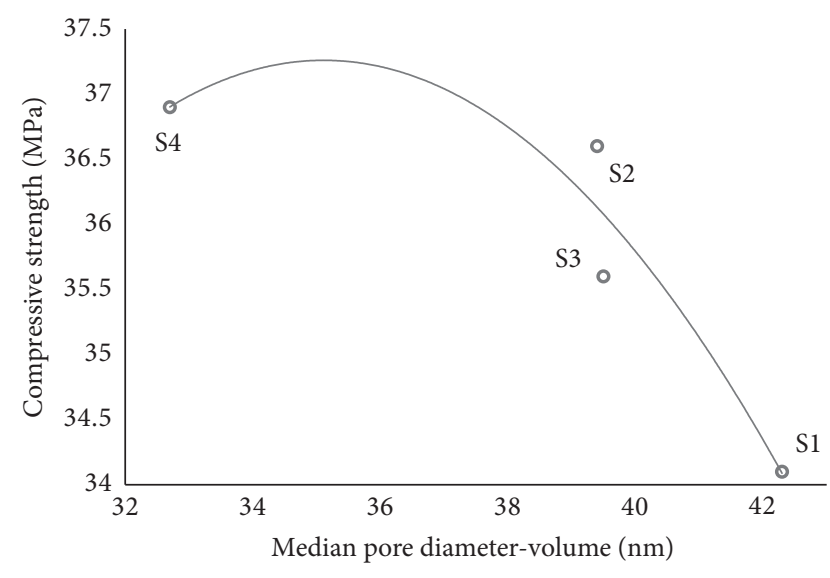

FIGURE 4: Relation between median pore diameter-volume and compressive strength.

by the placement of the formed hydration products in the pores. Median pore diameter-volume is also reduced with the use of aerogel at a constant activator dosage. This reduction is not due to the hydration products, however, it is because of the decrease observed in diameters by the effect of increasing aerogel content. As a natural consequence of this, the median pore diameter-volume decreases and therefore the compressive strengths increase.

By evaluating pore size distributions in mortar samples, it is seen that, in Figure 5, the samples tend to behave differently depending on their total porosity values. S4 and S1 samples, which have total porosity values of $13.5 \%$ and $11.4 \%$, exhibit a pore diameter distribution behavior that is independent of each other and S2-S3 samples, while S2-S3 samples with the total porosity value of $15.5 \%$ show similar behavior.

S2 and S3 samples exhibit similar behavior across all diameters along the graph. Unlike the other samples, pore diameters of $90,000 \mathrm{~nm}$ and above were found in these samples. In other samples, however, pore diameter greater than the value of about 7,000 nm was not measured. S2 and S3 samples are the ones exhibiting the highest cumulative pore volume behavior throughout all micro- and capillary pore diameter ranges. Similar cumulative pore volume-pore size distribution behavior of samples S2 and S3 is reflected in all mechanical and porosimetric parameters. The median pore diameter-volume values ( 39.4 and $39.5 \mathrm{~nm}$ ), median pore diameter-area values $(6.0$ and $5.8 \mathrm{~nm})$, total porosity values (15.53 and 15.48\%), and compressive strengths (35.6 and $36.6 \mathrm{MPa}$ ) of the samples are quite similar.

The maximum pore diameter determined in the S4 sample is $6,670 \mathrm{~nm}$. Throughout the graph, its porosimetric behavior almost coincides with the S1 sample in diameters of $1,000 \mathrm{~nm}$ and above, while it exhibits a lower cumulative pore volume behavior than the sample group of S2-S3. This porosimetric diameter distribution difference throughout the diameter range of 3 to $1,000 \mathrm{~nm}$ is reflected in the porosimetric parameters of the S4 and S1 samples.

Although the S1 sample behaves quite differently than the S2-S3 samples, it tends to exhibit a characteristic closer to the $\mathrm{S} 4$ sample since the highest pore diameter is detected

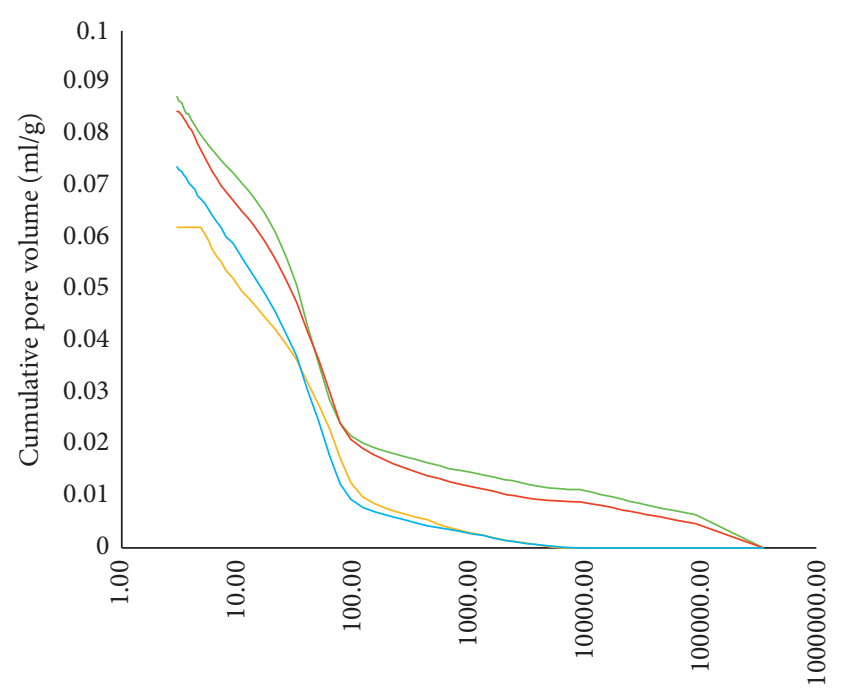

Pore diameter (nm)

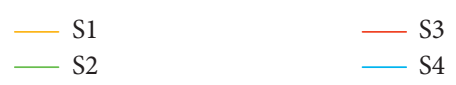

Figure 5: Pore size distributions.

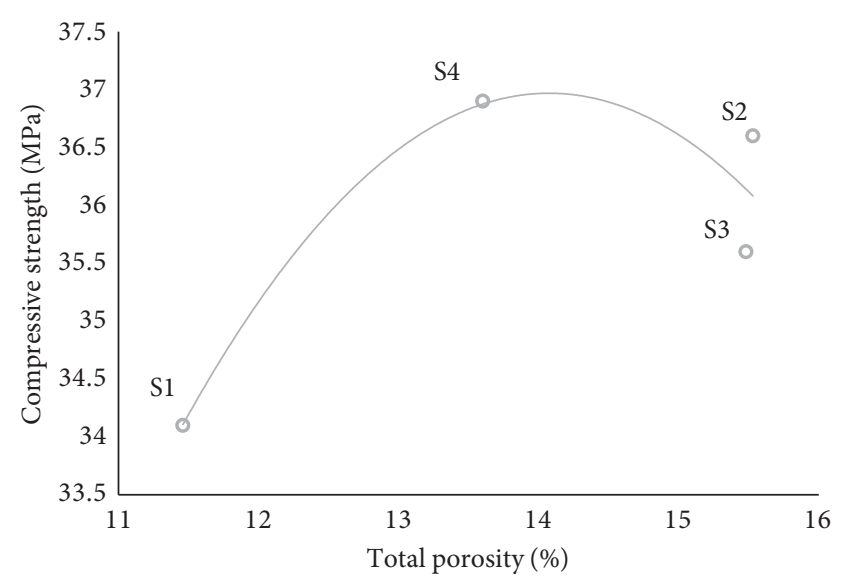

FIgURE 6: Relation between compressive strength and total porosity.

about $5,080 \mathrm{~nm}$. The lowest total porosity $(11.46 \%)$ and the highest median pore diameter-volume $(42.2 \mathrm{~nm})$ values were found due to the fact that it has the lowest cumulative pore volume value among all samples and exhibits its porosimetric properties at a limited diameter range.

Figure 6 shows the relationship between total porosity and 28-day compressive strengths in the mortar samples. Regarding previous experimental studies, it is known that aerogel content does not affect the hydration level of binding material. By means of increasing activator dosage ability of increasing the number of C-S-H bonds in the cement matrix in constant aerogel content, higher compressive strengths could be determined in sample S2 than S1 and, similarly, in S4 than S3. Adhesion between the matrix of binder material and the brittle aerogel particles during hydration is highly influenced by the activator dosage. The increased activator dosage in the low aerogel content rates (S1 and S2) increases 
TABLE 8: Thermal conductivity test results of aerogel-incorporated AAS mortars.

\begin{tabular}{ll}
\hline & Thermal conductivity $(\mathrm{W} / \mathrm{mK})$ \\
\hline S1 & 1.32 \\
S2 & 1.45 \\
S3 & 1.46 \\
S4 & 1.58 \\
\hline
\end{tabular}

the total porosity of the mortar by increasing the volume of the transitive zone formed between the aerogel particles and the binder matrix. At high aerogel content rates (S3 and S4), this effect created by increasing activator dosage is reduced and the influence on the total porosity of the mortar is reversed. This situation is clearly observed in Figure 1 for diameter distributions of $100,000 \mathrm{~nm}$ and above. For this reason, the effect of increasing activator dosage ability of increasing the number of C-S-H bonds in cement matrix is more effective than the change in total porosity on compressive strengths.

3.4. Thermal Conductivity Test Results. The thermal conductivity coefficient results of alkali-activated slag mortars are presented in Table 8 . In the experimental studies, the thermal conductivity coefficient results were found in the range of $1.32-1.58 \mathrm{~W} / \mathrm{mK}$.

The lowest thermal conductivity coefficient was $1.32 \mathrm{~W} / \mathrm{mK}$ at $\mathrm{S} 1$ sample with $0.75 \%$ aerogel content and $0.03 \% \mathrm{Li}_{2} \mathrm{CO}_{3}$ activator dosage. In this sample, the lowest conductivity coefficient was found due to the effect of the highest median pore diameter-volume value $(42.2 \mathrm{~nm})$ and the highest median pore diameter-area value $(8.8 \mathrm{~nm})$ differently from the other samples. Increasing aerogel content rate decreased median pore diameter-volume values (395 and $32.7 \mathrm{~nm})$ in the $\mathrm{S} 3(1.46 \mathrm{~W} / \mathrm{mK})$ and $\mathrm{S} 4(1.58 \mathrm{~W} / \mathrm{mK})$ samples, respectively, and lead to higher thermal conductivity coefficients (at rates of $10.6 \%$ and $19.6 \%$, resp.) in comparison with that in the S1 sample.

Although the S2 sample $(1.45 \mathrm{~W} / \mathrm{mK})$ has the same aerogel content as the $\mathrm{S} 1$ sample, the pore structure of the sample is similar to the S3 sample since the median pore diameter-volume value $(39.4 \mathrm{~nm})$ and median pore diameter-area value $(6.0 \mathrm{~nm})$ are developed due to the high $\mathrm{Li}_{2} \mathrm{CO}_{3}$ dosage. Therefore, almost the same conductivity coefficient as the S2 sample could be found at the sample S3.

Figure 7 shows the relationship between the median pore diameter-area values and the thermal conductivity coefficient in the mortar samples. The thermal conductivity coefficient increases with the increment of pore diameter up to the value around $6.5 \mathrm{~nm}$; however, the coefficient decreases with the increase in the diameter up to higher values. The thermal conductivity coefficients were $1.45-1.46 \mathrm{~W} / \mathrm{mK}$ for samples with $5.8-6.0 \mathrm{~nm}$ pore diameter and $1.58 \mathrm{~W} / \mathrm{mK}$ for samples with $6.6 \mathrm{~nm}$ pore diameter. The thermal conductivity coefficient has decreased to the minimum value when the median pore diameter-area value reached $8.8 \mathrm{~nm}$ for S1 sample.

Since the median pore diameter-area values of samples S2 and S3 are very close to each other, the thermal

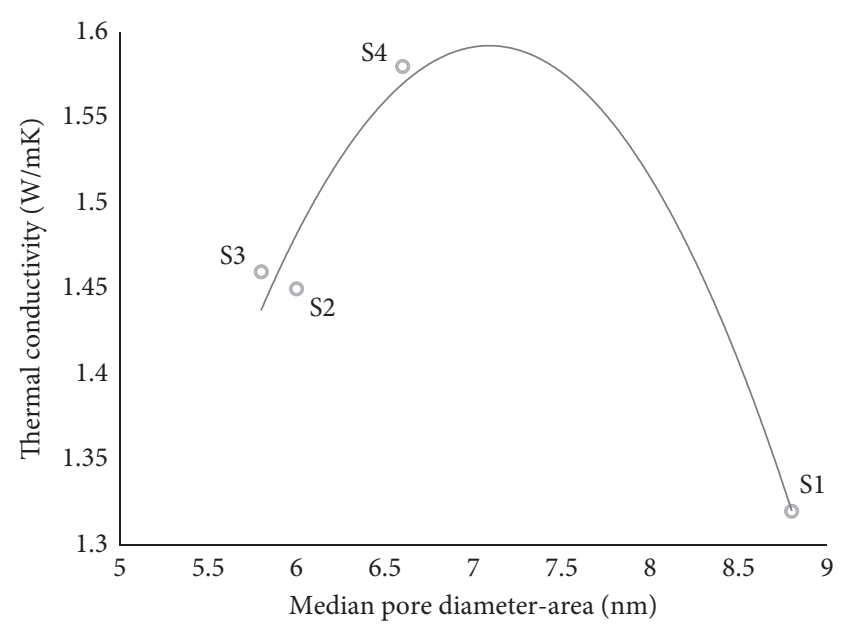

FIgURE 7: Relation between median pore diameter-area and thermal conductivity test results.

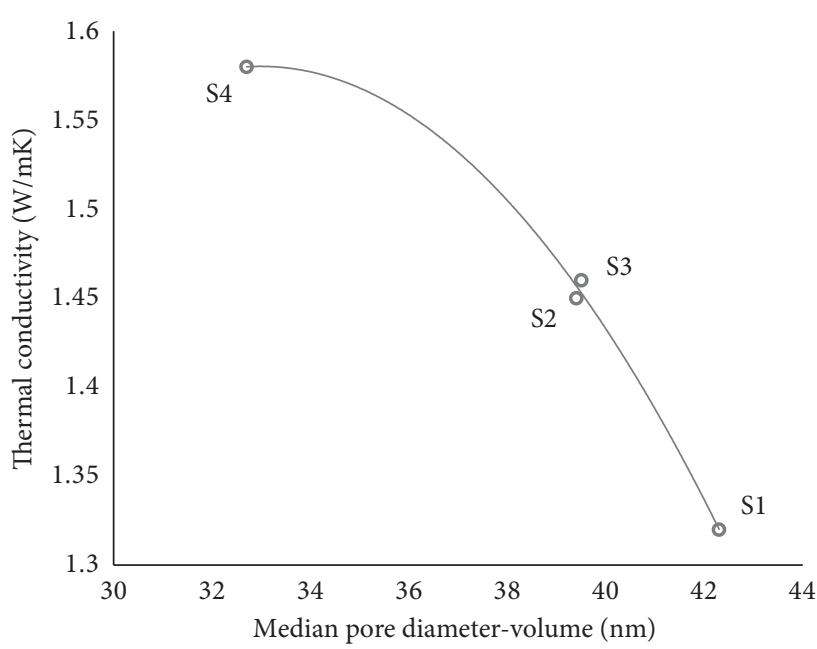

FIgURE 8: Relation between median pore diameter-volume and thermal conductivity test results.

conductivity coefficients are also very approximate to each other $(1.45$ and $1.46 \mathrm{~W} / \mathrm{mK})$. It is expected that the median pore diameter-area of S1 $(8.8 \mathrm{~nm})$ is larger than those of S2 and $\mathrm{S} 3$, and the thermal conductivity coefficient is also lower. S4 has a higher thermal conductivity coefficient, even though it has a higher median pore diameter-area than S2 and S3. The case is an unexpected issue. The evaluations made considering experimental findings, however, have shown that median pore diameter-volume gives better results than those with median pore diameter-area measurements. This is an important and promising result for MIP evaluations.

Figure 8 shows the relationship between the median pore diameter-volume values and the thermal conductivity coefficient in the mortar samples. The thermal conductivity coefficient tends to decrease depending on the increasing pore diameter value. In the samples with the similar pore diameter value of $39.4-39.5 \mathrm{~nm}$, the thermal conductivity coefficient was found relatively similar to $1.45-1.46 \mathrm{~W} / \mathrm{mK}$, respectively. The thermal conductivity coefficient has 


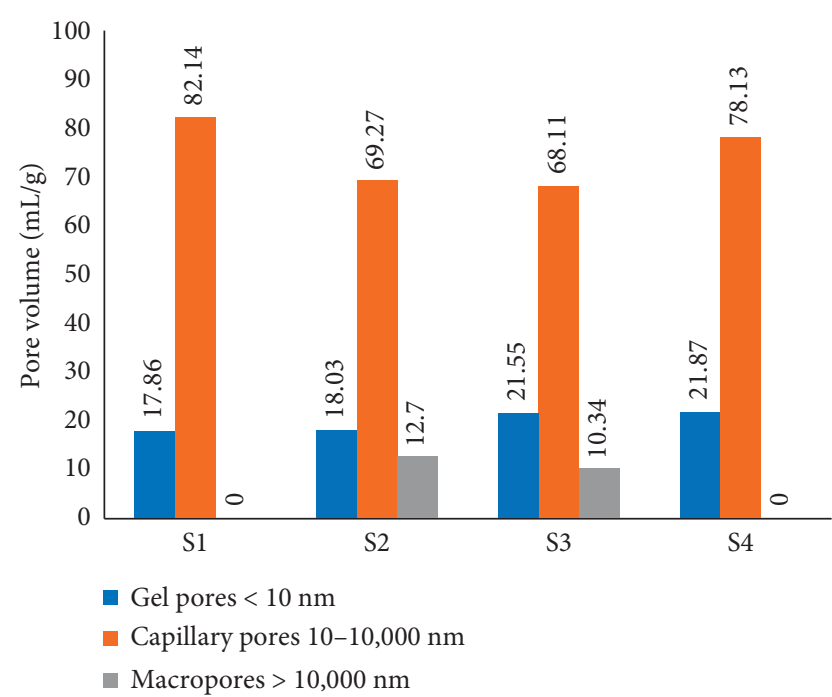

Figure 9: Pore volume of gel pores, capillary pores, and macropores for all samples obtained from MIP data.

decreased to the minimum value when the median pore diameter-volume value reached to $42.3 \mathrm{~nm}$ for S1 sample.

The percentage distribution of pore volumes in the total pore volume is shown in Figure 9. In the S1 sample at which the minimum thermal conductivity coefficient was found, minimum gel pore formation $(17.86 \%)$ and maximum capillary pore formation (82.14\%) exist compared to the other samples. In S2 and S3 samples which have compressive strengths and thermal conductivity coefficients close to each other, macropore formation in percentages of $12.7 \%$ and $10.35 \%$ was observed. In these samples, the formation of macropore increases the maximum total porosity values of the samples to 15.53 and $15.47 \%$ compared to the other samples; however, it could not ensure to decrease the conductivity coefficients to desired values.

\section{Conclusions}

(i) Increasing the aerogel content rates in equal activator dosaged samples causes negligible extension at both initial and final setting times while increasing $\mathrm{Li}_{2} \mathrm{CO}_{3}$ dosage in mortar mixtures shortens both initial and final setting times at mortar samples.

(ii) In the compressive strength test of aerogelincorporated AAS mortars performed for 2-, 7-, and 28-day curing times, the highest compressive strengths were obtained from the samples with high $\mathrm{Li}_{2} \mathrm{CO}_{3}$ doses $(1.5 \%)$ and the lowest strength values were determined at the samples with low $\mathrm{Li}_{2} \mathrm{CO}_{3}$ doses $(0.03 \%)$ for all curing times.

(iii) Partial strength increase was found with the incrementing aerogel additive ratio at 7- and 28day samples while increasing aerogel content causes the partial loss in compressive strengths at 2-day ones. By means of increasing aerogel content in the samples with equal dosages, the maximum strength loss measured at 2-day samples is $4.9 \%$. However, maximum strength increases were found as $0.9 \%$ and $1.4 \%$ at 7 - and 28 -day strength results for equal doses and increasing aerogel content rates.

(iv) Total porosity value tends to decrease due to the increasing median pore diameter-area value in the mortar samples.

(v) In aerogel-incorporated AAS mortar samples, median pore diameter-volume is more influential on compressive strength and thermal conductivity coefficient than the total porosity value. Since a satisfactorily high median pore diameter-volume value could not be detected in samples with higher total porosity and macropores, a significant reduction in the conductivity coefficient was not observed.

(vi) The compressive strengths decrease with the increasing median pore diameter-volume values. In the samples with the lowest total porosity, minimum compressive strength under the control of maximum median pore diameter-volume values was found. The diameter difference of $9.6 \mathrm{~nm}$ corresponds to $8.2 \%$ improvement in compressive strength.

(vii) Minimum thermal conductivity coefficient $(1.32 \mathrm{~W} / \mathrm{mK})$ was found by means of maximum median pore diameter-volume and maximum median pore diameter-area values at the $0.75 \%$ aerogel content rate and $0.03 \% \mathrm{Li}_{2} \mathrm{CO}_{3}$ dosage. At these rates, gel pore and capillary pore diameter formations are at the minimum (17.86\%) and maximum (82.14\%) levels, respectively.

(viii) The high correlation between compressive strength-median pore diameter-volume values remains valid in also between thermal conductivity coefficient-median pore diameter-volume values. The minimum thermal conductivity coefficient was found at the lowest total porosity value by means of the highest median pore diameter-area and median pore diameter-volume values.

(ix) Increasing activator dosage in equal aerogel content rates brings about an increase in thermal conductivity coefficient due to the decrease in median pore diameter-volume value.

\section{Data Availability}

All data generated or analysed during this study are included in this published article.

\section{Conflicts of Interest}

The authors declare that there are no conflicts of interest regarding the publication of this paper. 


\section{Acknowledgments}

The authors specially thank Head of Bolu Cement Factory and employees.

\section{References}

[1] K. L. Scrivener and R. J. Kirkpatric, "Innovation in use and research on cementitious material," Cement and Concrete Research, vol. 38, no. 2, pp. 128-136, 2008.

[2] J. H. Kim and H. S. Lee, "Improvement of early strength of cement mortar containing granulated blast furnace slag using industrial byproducts," Materials, vol. 10, no. 9, p. 1050, 2017.

[3] H. S. Lee and X. Y. Wang, "Evaluation of the carbon dioxide uptake of slag-blended concrete structures, considering the effect of carbonation," Sustainability, vol. 8, no. 4, p. 312, 2016.

[4] D. E. Angulo-Ramírez, R. M. Gutiérrez, and F. Puertas, "Alkali-activated Portland blast-furnace slag cement: mechanical properties and hydration," Construction and Building Materials, vol. 140, pp. 119-128, 2017.

[5] R. J. Myers, S. A. Bernal, and J. L. Provis, "Phase diagrams for alkali-activated slag binders," Cement and Concrete Research, vol. 95, pp. 30-38, 2017.

[6] T. Luukkonen, Z. Abdollahnejad, J. Yliniemi, P. Kinnunen, and M. Illikainen, "One-part alkali-activated materials: a review," Cement and Concrete Research, vol. 103, pp. 21-34, 2018.

[7] X. Huang, S. Hu, F. Wang, Y. Liu, and Y. Mu, "Properties of alkali-activated slag with addition of cation exchange material," Construction and Building Materials, vol. 146, pp. 321328, 2017.

[8] A. Fernandez-Jimenez and F. Puertas, "Effect of activator mix on the hydration and strength behaviour of alkali-activated slag cements," Advances in Cement Research, vol. 15, no. 3, pp. 129-136, 2003.

[9] J. J. Chang, "A study on the setting characteristics of sodium silicate-activated slag pastes," Cement and Concrete Research, vol. 33, no. 7, pp. 1005-1011, 2003.

[10] M. Najimi, N. Ghafoori, and M. Sharbaf, "Alkali-activated natural pozzolan/slag mortars: a parametric study," Construction and Building Materials, vol. 164, pp. 625-643, 2018.

[11] C. Shi, "Strength, pore structure and permeability of alkaliactivated slag mortars," Cement and Concrete Research, vol. 26, no. 12, pp. 1789-1799, 1996.

[12] F. Collins and J. G. Sanjayan, "Effect of pore size distribution on drying shrinkage of alkali-activated slag concrete," Cement and Concrete Research, vol. 30, no. 9, pp. 1401-1406, 2000.

[13] C. Shi, R. L. Day, X. Wu, and M. Tang, "Uptake of metal ions by autoclaved cement pastes," MRS Proceedings, vol. 245, pp. 141-149, 1992.

[14] M. D. Jalal, A. Tanveer, K. Jagdeesh, and F. Ahmed, "Foam concrete," International Journal of Civil Engineering Research, vol. 8, pp. 1-14, 2017.

[15] E. Cohen, "Thermal properties of advanced aerogel insulation," M.S. dissertation, Massachusetts Institute of Technology, Cambridge, MA, USA, 2011.

[16] A. C. Pierre and G. M. Pajonk, "Chemistry of aerogels and their applications," Chemical Reviews, vol. 102, no. 11, pp. 4243-4265, 2002.

[17] M. A. Hasan, R. Sangashetty, A. C. M. Esther, S. B. Patil, B. N. Sherikar, and A. Dey, "Prospect of thermal insulation by silica aerogel: a brief review," Journal of The Institution of Engineers (India): Series D, vol. 98, no. 2, pp. 297-304, 2017.
[18] P. Westgate, K. Paine, and R. J. Ball, "Physical and mechanical properties of plasters incorporating aerogel granules and polypropylene monofilament fibres," Construction and Building Materials, vol. 158, pp. 472-480, 2018.

[19] T. Gao, B. P. Jelle, A. Gustavsen, and S. Jacobsen, "Aerogelincorporated concrete: an experimental study," Construction and Building Materials, vol. 52, pp. 130-136, 2014 


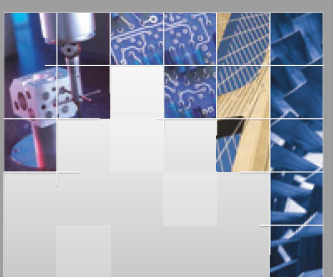

\section{Enfincering}
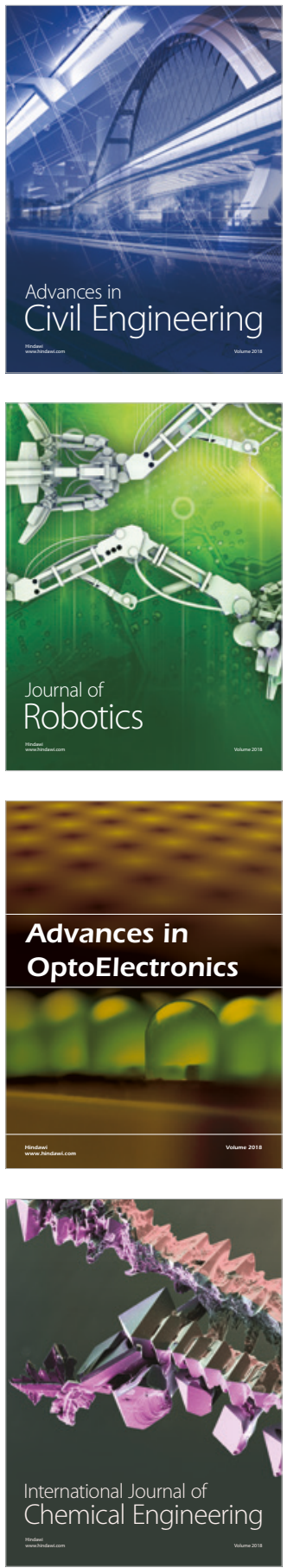

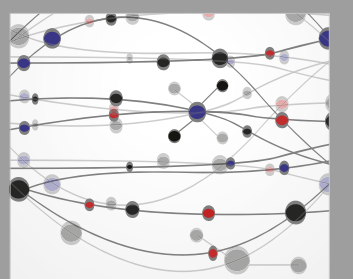

\section{Rotating \\ Machinery}

The Scientific World Journal

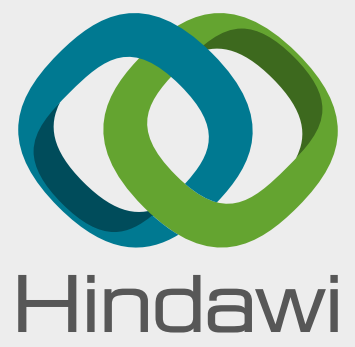

Submit your manuscripts at

www.hindawi.com
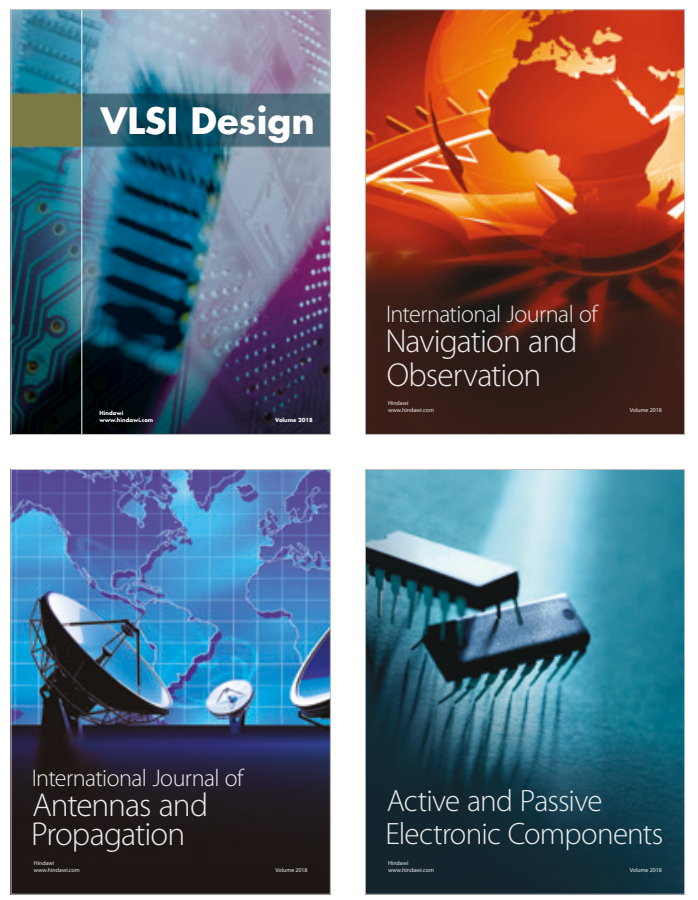
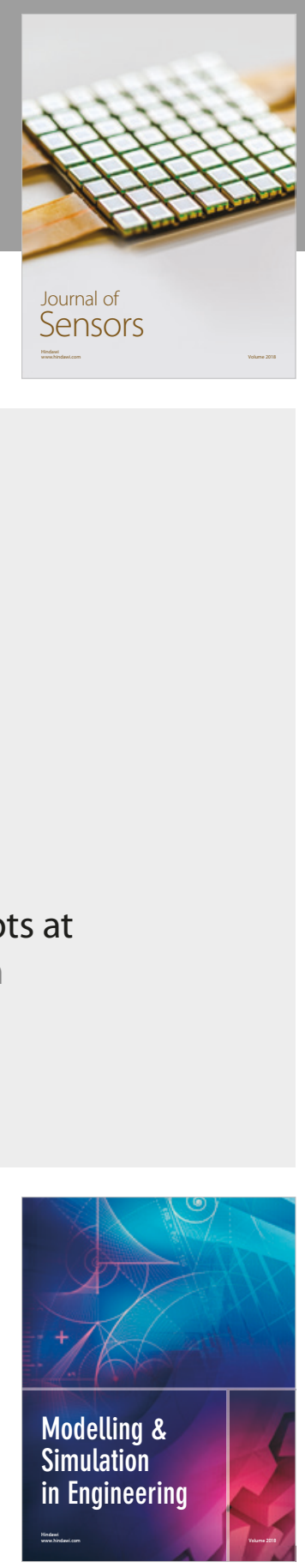

\section{Advances \\ Multimedia}
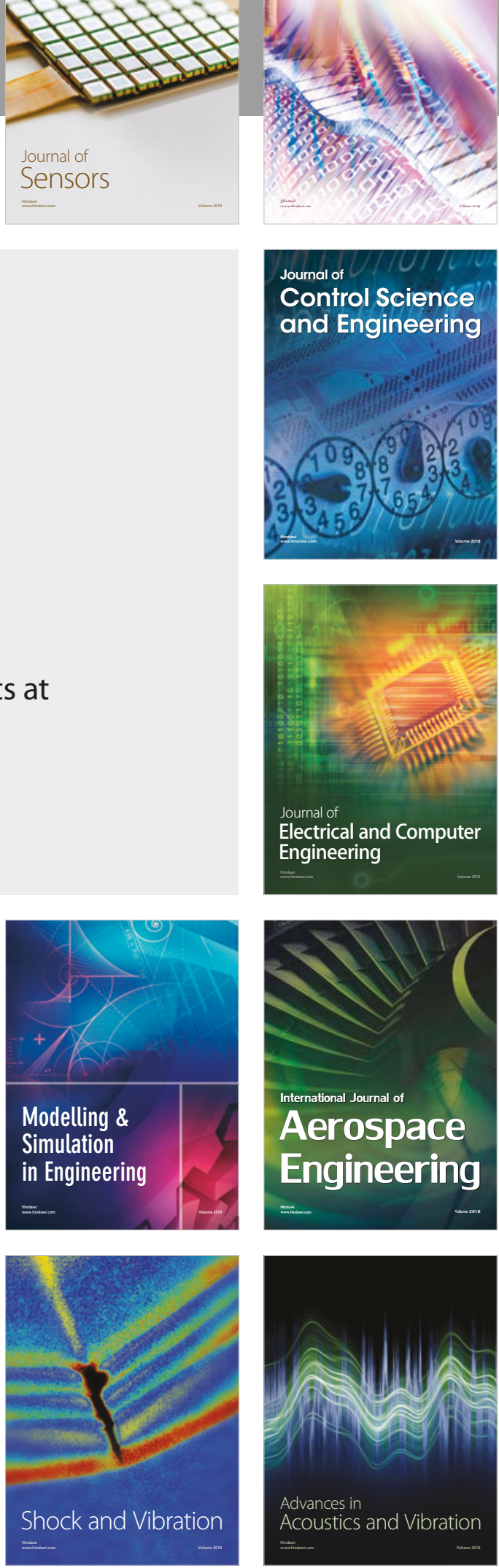